\title{
An in vitro evaluation of antibacterial activity of various extracts of Achyranthes aspera and Cissus quadrangularis
}

\author{
V. Sureshkumar*, S. Rajagunalan ${ }^{1}$ and S. Malmarugan ${ }^{1}$ \\ Department of Veterinary Pharmacology and Toxicology, Veterinary College and Research Institute \\ (TNVASU), Tirunelveli (T.N.) India (Email: drsurpha@gmail.com)
}

\begin{abstract}
The antibacterial activity of aqueous and methanol extracts of Achyranthes aspera and Cissus quadrangularis was evaluated. A. aspera and C. quadrangularis plants collected from its natural habitat in and around Tirunelveli, Tamil Nadu, India were shadow dried at room temperature and pulverized into coarse powder. Aqueous extracts were prepared by extracting with distilled water at $100^{\circ} \mathrm{C}$ for $4 \mathrm{~h}$ and methanol extracts were prepared by maceration process using methanol for $72 \mathrm{~h}$. The aqueous extract yield was $12.1 \%$ and $23.5 \%$ for $A$. aspera and C. quadrangularis respectively. Whereas, methanol extract yield was $6 \%$ and $4 \%$ for A. aspera and C. quadrangularis, respectively. The antibacterial activity of plant extracts against Staphylococcus aureus (MTCC-96) and Escherichia coli (MTCC-443) was evaluated by Agar well diffusion method. The diameters of zone of inhibition ranged from $8 \mathrm{~mm}$ to $17 \mathrm{~mm}$ with highest inhibition zone observed against $S$. aureus by methanol extract of $A$. aspera $(17 \mathrm{~mm})$ followed by aqueous extract of $C$. quadrangularis $(13 \mathrm{~mm})$ and methanol extract of $C$. quadrangularis $(9 \mathrm{~mm})$. Whereas, zone of inhibition (8mm) against Escherichia coli was observed only with methanol extract of $C$. quadrangularis. The results necessitate further study to isolate the active principles from the plant extracts to exploit the potential antibacterial activity and to find novel pharmacological uses of these plants beyond their racial use.
\end{abstract}

Key Words : Achyranthes aspera, Cissus quadrangularis, Aqueous extract, Methanol extract, Antibacterial activity, ABST

View Point Article : Sureshkumar, V., Rajagunalan, S. Malmarugan, S. (2021). An in vitro evaluation of antibacterial activity of various extracts of Achyranthes aspera and Cissus quadrangularis. Internat. J. agric. Sci., 17 (2) : 365-370, DOI:10.15740/HAS/IJAS/17.2/365370. Copyright@2021: Hind Agri-Horticultural Society.

Article History : Received : 25.02.2021; Revised : 27.02.2021; Accepted : 16.03.2021

\footnotetext{
* Author for correspondence :

${ }^{1}$ Department of Veterinary Public Health and Epidemiology, Veterinary College and Research Institute (TNVASU), Tirunelveli (T.N.) India
} 